\title{
STATUS KEBERSIHAN GIGI DAN MULUT PADA NELAYAN DI KELURAHAN BAHU KECAMATAN MALALAYANG KOTA MANADO SULAWESI UTARA
}

\author{
${ }^{1}$ Gary S. J. Nayoan \\ ${ }^{2}$ Damajanty H. C. Pangemanan, \\ ${ }^{3}$ Christy N. Mintjelungan
}

\author{
${ }^{1}$ Kandidat Skripsi Program Studi Pendidikan Dokter Gigi Fakultas Kedokteran \\ ${ }^{2}$ Bagian Fisiologi Fakultas Kedokteran \\ ${ }^{3}$ Program Studi Pendidikan Dokter Gigi Fakultas Kedokteran \\ Universitas Sam Ratulangi Manado \\ Email: garysjnayoan@yahoo.com
}

\begin{abstract}
Oral hygiene is a part of the general health that is needed to be considered by the community. Some causes of a person neglecting his/her teeth and mouth cleanliness are level of education, level of knowledge, and the person's income. Generally, fishermen do not have enough time to take care of their oral hygiene. This study aimed to determine the status of oral hygiene of fishermen living in Bahu Malalayang Manado, North Sulawesi. This was a descriptive study using a cross sectional design. There were 63 fishermen, but only 38 fulfilled the inclusion and exclusion criteria. The results showed that based on the knowledge, most of the dental and oral hygiene status (62.52\%) belonged to the medium category of OHI-S. Oral hygiene status Based on the characteristics of age, most of the age group of 36-45 years (61.29\%) had the medium category of OHI-S. Distribution of oral hygiene status by education was most dominant subjects with secondary school education level that is equal to $81,82 \%$. Distribution of oral hygiene status by income is most prevalent subject to income <UMP included in category status OHI-S was in the amount of $60.00 \%$.
\end{abstract}

Keywords: status of oral hygiene, fisherman

\begin{abstract}
Abstrak: Kebersihan gigi dan mulut merupakan bagian dari kesehatan secara umum yang perlu diperhatikan oleh masyarakat. Beberapa faktor penyebab seseorang mengabaikan kebersihan gigi dan mulutnya yaitu diantaranya tingkat pendidikan, tingkat pengetahuan, dan penghasilan. Kegiatan perikanan para nelayan yang sehari semalam berada dilaut menyebabkan perhatian terhadap kebersihan gigi dan mulut menjadi kurang. Penelitian ini bertujuan untuk mengetahui status kebersihan gigi dan mulut pada nelayan di kelurahan Bahu kecamatan Malalayang kota Manado Sulawesi Utara. Penelitian ini bersifat deskriptif menggunakan pendekatan potong lintang, dilakukan pada nelayan yang berada di kelurahan Bahu kecamatan Malalayang kota Manado Sulawesi Utara yang berjumlah 63 orang, namun sampel yang didapat berdasarkan kriteria inklusi dan eksklusi yaitu berjumlah 38 orang. Hasil penelitian menunjukkan bahwa berdasarkan pengetahuan paling banyak ditemukan pada kategori OHI-S sedang (65,52\%). Status kebersihan gigi dan mulut berdasarkan karakteristik usia lebih banyak ditemukan pada kategori usia 36-45 tahun yang memiliki status OHI-S sedang (61,29\%). Distribusi berdasarkan pendidikan paling banyak ditemukan tingkat pendidikan SMA dengan status OHI-S sedang (81,82\%). Distribusi berdasarkan penghasilan paling banyak ditemukan penghasilan lebih kecil dari UMP yang termasuk dalam kategori status OHI-S (60,00\%).
\end{abstract}

Kata kunci: status kebersihan gigi dan mulut, nelayan 
Indonesia mempunyai lautan yang lebih luas dari daratan. Dua pertiga wilayah Indonesia ialah perairan laut yang terdiri dari laut pesisir, laut lepas, teluk dan selat. ${ }^{1}$ Luas wilayah laut termasuk di dalamnya Zona Ekonomi Eksklusif mencapai 5,8 km² atau sekitar 3/4 dari luas keseluruhan wilayah Indonesia. ${ }^{2}$ Wilayah laut dan pesisir merupakan wilayah yang amat penting bagi sebagian besar penduduk Indonesia. Lebih dari empat belas juta penduduk atau sekitar $7,5 \%$ dari total penduduk Indonesia menggantungkan hidupnya pada pekerjaan yang ada di wilayah laut dan pesisir pantai. ${ }^{3}$

Sebagai suatu kesatuan sosial, masyarakat nelayan hidup, tumbuh, dan berkembang di wilayah pesisir atau wilayah pantai. Meskipun disadari bahwa tidak semua desa-desa di kawasan pesisir memiliki penduduk yang bermata pencaharian sebagai nelayan. ${ }^{4}$ Nelayan yang sehari-hari melakukan pekerjaan yang dapat dikatakan membutuhkan keberanian dan tenaga yang lebih dari pekerjan lainnya terkadang membuat nelayan lupa akan kesehatannya, begitu juga dengan kesehatan gigi dan mulutnya. Kesehatan mulut sangat dipengaruhi oleh kebersihan gigi dan mulut itu sendiri. ${ }^{5}$

Di Indonesia masalah kesehatan gigi dan mulut tergolong tinggi, berdasarkan data yang didapat dari Riset Kesehatan Dasar (RISKESDAS) 2013 bahwa sebesar 25,9\% penduduk Indonesia mempunyai masalah kesehatan gigi dan mulut dalam 12 bulan terakhir. Angka prevalensi tertinggi terhadap masalah kesehatan gigi dan mulut terdapat di provinsi Sulawesi Selatan 36,2\% diikuti Kalimantan Selatan 36,1\%, Sulawesi Tengah 35,6\%, Sulawesi Barat 32,2\%, DI Yoyakarta 32,1\%, Sulawesi Utara 31,6\%. Sulawesi Utara merupakan salah satu dari enam provinsi yang memiliki nilai tertinggi dalammasalah kesehatan gigi dan mulut dengan prevalensi sebesar 31,6\%. ${ }^{6}$

Berdasarkan teori Blum, status kesehatan gigi dan mulut seseorang atau masyarakat dipengaruhi oleh empat faktor penting yaitu keturunan, lingkungan (fisik maupun sosial budaya), perilaku, dan pelayanan kesehatan. Dari keempat faktor tersebut, faktor lingkungan baik itu lingkungan fisik maupun sosial budaya yang diantaranya ialah tingkat pendidikan, tingkat pengetahuan, dan penghasilan, memegang peranan penting dalam memengaruhi status kesehatan gigi dan mulut para nelayan. ${ }^{7}$ Seperti penelitian yang dilakukan oleh Fitriyansyah 2013 bahwa sekitar 3,33\% nelayan di Pulau Kodingareng memiliki keadaan kebersihan mulut yang baik, sekitar 30\% memiliki kebersihan mulut yang sedang, dan sekitar 66,66\% atau lebih dari setengah nelayan di Pulau Kodingareng memiliki kebersihan mulut yang buruk. ${ }^{8}$

Umur juga memengaruhi pengetahuan dan kebersihan gigi dan mulut. Berdasarkan Departemen Kesehatan Republik Indonesia (DEPKES RI) pada tahun 2009 menunjukan masa dewasa awal dan akhir ada pada umur 26-45 tahun. Nelayan di kelurahan Bahu bekerja dengan waktu yang bervariatif, tergantung dari rejeki yang diperoleh, bahkan terkadang beberapa dari mereka berada di laut sehari semalam. Hal ini menyebabkan perhatian terhadap kebersihan gigi menjadi kurang. Namun itu hanya salah satu dari beberapa hal yang menjadi penyebab. Oleh karena itu peneliti tertarik untuk melakukan penelitian mengenai status kebersihan gigi dan mulut pada nelayan di kelurahan Bahu Kecamatan Malalayang Kota Manado Sulawesi Utara.

\section{METODE PENELITIAN}

Penelitian ini merupakan penelitian deskriptif dengan menggunakan desain potong lintang. Penelitian dilaksanakan di kelurahan Bahu kecamatan Malalayang kota Manado Sulawesi Utara pada bulan Oktober tahun 2015. Total populasi nelayan di kelurahan Bahu sebesar 63 orang dan berdasarkan kriteria inklusi dan eksklusi didapatkan sampel sebanyak 38 orang.

Variabel penelitian ini yaitu status kebersihan gigi dan mulut (OHI-S), Karakteristik usia, Pengetahuan, 
Pendidikan dan Penghasilan. Penelitian dimulai sesuai dengan tanggal yang telah disetujui oleh kepala kelurahan Bahu kecamatan Malalayang kota Manado Sulawesi Utara. Nelayan yang diperiksa diberikan surat persetujuan tertulis berupa informed consent sebelum dilakukan pemeriksaan. Pengambilan data mengenai pengetahuan kesehatan gigi dan mulut dinilai melalui pengisian kuesioner, kemudian dilakukan pemeriksaan status kebersihan gigi dan mulut dengan menggunakan indeks OHI-S.

Langkah-langkah kerjanya yaitu operator mengajukan pertanyaanpertanyaan dari kuesioner kemudian dijawab oleh responden. Setelah itu, responden duduk tenang dengan posisi kepala sedikit diangkat kemudian diinstruksikan membuka mulut untuk dilihat keadaan gigi yang akan diperiksa. Responden diperiksa dengan menggunakan alat diagnostik berupa kaca mulut dan sonde, kemudian dinilai indeks OHI-Snya (Debris Indeks dan Kalkulus Indeks). Data diolah berdasarkan distribusi frekuensi kebersihan mulut berdasarkan karakteristik usia, pengetahuan, status pendidikan dan pendapatan kemudian dianalisis dan disajikan dalam bentuk tabel dengan menggunakan program komputer.

\section{HASIL PENELITIAN}

Subjek penelitian diteliti berdasarkan karakteristik usia, tingkat pengetahuan, tingkat pendidikan, dan tingkat penghasilan. Distribusi subjek penelitian berdasarkan karakteristik usia dapat dilihat pada Tabel 1. Distribusi subjek penelitian berdasarkan tingkat pengetahuan dapat dilihat pada Tabel 2. Distribusi subjek penelitian berdasarkan tingkat pendidikan dapat dilihat pada Tabel 3. Distribusi subjek penelitian berdasarkan tingkat penghasilan dapat dilihat pada Tabel 4 . Distribusi status kebersihan gigi dan mulut responden dapat dilihat pada Tabel 5 . Distribusi status kebersihan gigi dan mulut berdasarkan karakteristik usia dapat dilihat pada Tabel 6. Distribusi status kebersihan gigi dan mulut berdasarkan pengetahuan dapat dilihat pada Tabel 7. Distribusi status kebersihan gigi dan mulut berdasarkan pendidikan dapat dilihat pada Tabel 8 . Distribusi status kebersihan gigi dan mulut berdasarkan penghasilan dapat dilihat pada Tabel 9.

Tabel 1. Distribusi subjek penelitian berdasarkan karakteristik usia

\begin{tabular}{ccc}
\hline $\begin{array}{c}\text { Karakteristik } \\
\text { Usia (tahun) }\end{array}$ & (n) & (\%) \\
\hline $26-35$ & 7 & 18,42 \\
$36-45$ & 31 & 81,58 \\
\hline Total & 38 & 100,00 \\
\hline
\end{tabular}

Tabel 2. Distribusi subjek penelitian berdasarkan tingkat pengetahuan

\begin{tabular}{ccc}
\hline Pengetahuan & $(\mathrm{n})$ & $(\%)$ \\
\hline Baik & 29 & 76,32 \\
Sedang & 5 & 13,16 \\
Kurang & 4 & 10,52 \\
\hline Total & 38 & 100,00 \\
\hline
\end{tabular}

Tabel 3. Distribusi subjek penelitian berdasarkan tingkat pendidikan

\begin{tabular}{ccc}
\hline Pendidikan & $(\mathrm{n})$ & $(\%)$ \\
\hline SD & 11 & 28,95 \\
SMP & 16 & 42,10 \\
SMA & 11 & 28,95 \\
\hline Total & 38 & 100,00 \\
\hline
\end{tabular}

Tabel 4. Distribusi subjek penelitian berdasarkan tingkat penghasilan

\begin{tabular}{ccc}
\hline Penghasilan & $(\mathrm{n})$ & $(\%)$ \\
\hline$>$ UMP & 8 & 21,05 \\
$<$ UMP & 30 & 78,95 \\
\hline Total & 38 & 100,00 \\
\hline
\end{tabular}

Tabel 5. Distribusi status kebersihan gigi dan mulut responden

\begin{tabular}{ccc}
\hline OHI-S & $(\mathrm{n})$ & $(\%)$ \\
\hline Baik & 2 & 5.26 \\
Sedang & 23 & 60.53 \\
Buruk & 13 & 34.21 \\
\hline Total & 38 & 100.00 \\
\hline
\end{tabular}


Nayoan, Pangemanan, Mintjelungan: Status kebersihan gigi...

Tabel 6. Distribusi status kebersihan gigi dan mulut berdasarkan karakteristik usia

\begin{tabular}{|c|c|c|c|c|c|c|c|c|}
\hline \multirow{3}{*}{$\begin{array}{l}\text { Karakteristik } \\
\text { Usia (tahun) }\end{array}$} & & & \multicolumn{4}{|c|}{ Status OHI-S } & \multicolumn{2}{|c|}{ Total } \\
\hline & \multicolumn{2}{|c|}{ Baik } & \multicolumn{2}{|c|}{ Sedang } & \multicolumn{2}{|c|}{ Buruk } & & \\
\hline & $\bar{n}$ & $\%$ & $\mathrm{n}$ & $\%$ & $\mathrm{n}$ & $\%$ & $\mathrm{n}$ & $\%$ \\
\hline $26-35$ & 1 & 14,29 & 4 & 57,14 & 2 & 28,57 & 7 & 100,00 \\
\hline $36-45$ & 1 & 3,23 & 19 & 61,29 & 11 & 35,48 & 31 & 100,00 \\
\hline
\end{tabular}

Tabel 7. Distribusi status kebersihan gigi dan mulut berdasarkan pengetahuan

\begin{tabular}{lcccccccc}
\hline Pengetahuan & \multicolumn{4}{c}{ Status OHI-S } & \multicolumn{3}{c}{ Total } \\
\cline { 2 - 10 } & \multicolumn{2}{c}{ Baik } & \multicolumn{2}{c}{ Sedang } & \multicolumn{2}{c}{ Buruk } & & \\
\cline { 2 - 10 } & $\mathrm{n}$ & $\%$ & $\mathrm{n}$ & $\%$ & $\mathrm{n}$ & $\%$ & $\mathrm{n}$ & $\%$ \\
\hline Baik & 2 & 6,90 & 19 & 65,52 & 8 & 27,59 & 29 & 100,00 \\
Sedang & 0 & 0,00 & 3 & 60,00 & 2 & 40,00 & 5 & 100,00 \\
Kurang & 0 & 0,00 & 1 & 25,00 & 3 & 75,00 & 4 & 100,00 \\
\hline
\end{tabular}

Tabel 8. Distribusi status kebersihan gigi dan mulut berdasarkan pendidikan

\begin{tabular}{lcccccccc}
\hline Pendidikan & \multicolumn{9}{c}{ Status OHI-S } & \multicolumn{3}{c}{ Total } \\
\cline { 2 - 9 } & \multicolumn{2}{c}{ Baik } & \multicolumn{2}{c}{ Sedang } & \multicolumn{2}{c}{ Buruk } & & \\
\cline { 2 - 9 } & $\mathrm{n}$ & $\%$ & $\mathrm{n}$ & $\%$ & $\mathrm{n}$ & $\%$ & $\mathrm{n}$ & $\%$ \\
\hline SD & 1 & 9,09 & 6 & 54,55 & 4 & 36,36 & 11 & 100,00 \\
SMP & 0 & 0,00 & 8 & 50,00 & 8 & 50,00 & 16 & 100,00 \\
SMA & 1 & 9,09 & 9 & 81,82 & 1 & 9,09 & 11 & 100,00 \\
\hline
\end{tabular}

Tabel 9. Distribusi status kebersihan gigi dan mulut berdasarkan penghasilan

\begin{tabular}{|c|c|c|c|c|c|c|c|c|}
\hline \multirow[t]{3}{*}{ Penghasilan } & & & \multicolumn{4}{|c|}{ Status OHI-S } & \multicolumn{2}{|c|}{ Total } \\
\hline & \multicolumn{2}{|c|}{ Baik } & \multicolumn{2}{|c|}{ Sedang } & \multicolumn{2}{|c|}{ Buruk } & & \\
\hline & $\mathrm{n}$ & $\%$ & $\mathrm{n}$ & $\%$ & $\mathrm{n}$ & $\%$ & $\mathrm{n}$ & $\%$ \\
\hline$>$ UMP & 0 & 0,00 & 5 & 62,50 & 3 & 37,50 & 8 & 100,00 \\
\hline$<$ UMP & 2 & 6,67 & 18 & 60,00 & 10 & 33,33 & 30 & 100,00 \\
\hline
\end{tabular}

\section{BAHASAN}

Pada penelitian ini subjek penelitian terbagi atas dua kelompok usia yaitu 26-35 tahun yang merupakan masa dewasa awal dan 36-45 tahun yang merupakan masa dewasa akhir. Persentasi pada penelitian ini lebih banyak ditemui pada kelompok usia 36-45 tahun yaitu berjumlah 31 orang (81.58\%) daripada subjek yang berada pada kelompok usia 26-35 tahun yaitu 7 orang (18.42\%). Hal ini disebabkan karena sampel yang berusia 36-45 tahun merupakan kelompok usia dewasa akhir yang lebih peduli terhadap masalah kesehatan gigi dan mulut daripada yang berusia 26-35 yang tergolong dalam masa dewasa awal. Hal ini menunjukkan bahwa usia merupakan salah satu faktor yang memengaruhi perilaku kesehatan seseorang. Seperti yang dikatakan oleh Rasyid ${ }^{9}$ dalam bukunya bahwa usia merupakan salah satu faktor yang dapat menentukan kematangan seseorang baik dalam berfikir, bertindak maupun belajar. Kematangan dalam berfikir seseorang dapat memengaruhi baik pengetahuan, sikap, maupun praktek seseorang.

Persentasi status kebersihan gigi dan mulut berdasarkan karakteristik usia pada penelitian ini lebih banyak ditemui pada kelompok usia 36-45 dengan status kebersihan gigi dan mulut sedang yaitu 
berjumlah 19 orang $(61,29 \%)$ daripada kelompok usia 26-35 dengan status kebersihan gigi dan mulut sedang yang hanya berjumlah 4 orang $(57,14 \%)$. Hal ini disebabkan karena pengetahuan seseorang semakin bertambah seiring dengan bertambahnya usia. Seperti penelitian yang dilakukan oleh Indirawati dan Lelly ${ }^{10}$ di Pulo Gadung tahun 2013 bahwa subjek yang berusia di atas 37 tahun memiliki OHI-S baik sedangkan subjek yang berusia di bawah 37 tahun memiliki OHI-S buruk.

Persentasi pada penelitian ini menunjukkan bahwa sebagian besar subjek yang diteliti berpengetahuan baik yaitu berjumlah 29 orang $(76,32 \%)$ dan hanya 4 orang (10,53\%) yang berpengetahuan buruk. Persentasi status kebersihan gigi dan mulut berdasarkan tingkat pengetahuan pada penelitian ini terbanyak ditemui pada subjek yang berpengetahuan baik dengan kategori OHI-S sedang yaitu berjumlah 19 orang (65,52\%). Angka yang diperoleh menunjukkan bahwa rata-rata pengetahuan responden dalam hal kesehatan gigi dan mulut tergolong baik. Beberapa faktor yang dapat memengaruhi tingkat pengetahuan seseorang, antara lain yaitu faktor usia responden, pendidikan, dan penghasilan. Latar belakang usia responden turut memengaruhi pengetahuan yang dimiliki responden, karena menurut Yulianti dan Abi $^{11}$ usia memengaruhi daya tangkap dan pola pikir seseorang. Semakin bertambah usia akan semakin berkembang pula daya tangkap dan pola pikirnya, sehingga pengetahuan yang diperoleh semakin membaik. Tahapan kehidupan yang telah dijalani seseorang dapat memberikan suatu pengalaman yang tidak mudah dilupakan.

Tinggi rendahnya pengetahuan responden menurut pendapat penulis juga dipengaruhi oleh pendidikan formal maupun nonformal yang diterima responden. Hal ini tidak terlepas dari pendidikan yang diperoleh dalam keluarga. Lingkungan keluarga sangat besar pengaruhnya pada pembentukan pengetahuan individu. Pengetahuan yang diperoleh melalui bangku pendidikan formal, turut menambah dan melengkapi pengetahuan responden di bidang kesehatan gigi dan mulut. Hal ini sama dengan pernyataan dari Mubarak $^{12}$ yaitu pengetahuan turut dipengaruhi oleh faktor pendidikan. Semakin tinggi pendidikan seseorang, maka semakin mudah untuk menerima informasi, dan pada akhirnya semakin banyak pula pengetahuan yang dimilikinya. Sebaliknya, jika seseorang memiliki tingkat pendidikan yang rendah maka akan menghambat perkembangan seseorang untuk memperoleh informasi atau pengetahuan yang disampaikan.

Status sosial ekonomi responden menurut penulis turut memengaruhi tingkat pengetahuannya. Kondisi sosial ekonomi responden tergambar melalui besarnya penghasilan yang didapatkan setiap bulannya. Hal ini didukung oleh pernyataan dari Setiadi ${ }^{13}$ dalam tulisannya yang menyatakan bahwa status ekonomi seseorang juga akan menentukan tersedianya suatu fasilitas yang diperlukan untuk kegiatan tertentu, sehingga pengetahuan seseorang semakin baik.

Penelitian ini menunjukkan bahwa berdasarkan tingkat pendidikan sebagian besar subjek yang diteliti ada pada tingkat SMP dengan 16 orang tetapi status OHI-S terbanyak berada pada tingkat SMA dengan kategori sedang dengan 9 orang(81,82\%). Dilihat dari data di atas menunjukkan bahwa semakin tinggi tingkat pendidikan seseorang maka kebersihan gigi dan mulut akan semakin baik. Hal ini didukung oleh penelitian Sintawati dan Tjajah ${ }^{14}$ di DKI Jakarta tahun 2007 menyatakan bahwa faktor pendidikan memengaruhi kesehatan gigi dan mulut yaitu pendidikan di atas SMP memiliki peluang yang besar untuk OHI-S baik dibandingkan di bawah SMP. Hal ini sejalan dengan penelitian dari Setiawati di kawasan buruh PT Marukidaya bahwa seseorang yang berasal dari pendidikan rendah seperti tamatan sekolah dasar akan memiliki kesehatan gigi dan mulut yang buruk. ${ }^{15}$ Hasil ini juga sependapat dengan penelitian Sondang tahun 2008 di kecamatan Medan Tuntungan menunjukkan bahwa seseorang yang memiliki tingkat pendidikan rendah 
kemungkinan akan memiliki pengetahuan yang kurang mengenai kesehatan gigi dan mulut. ${ }^{16}$ Terlihat bahwa pendidikan sangat penting dalam pemeliharaan kesehatan karena menurut Tirt Hankar pendidikan ialah salah satu faktor yang memengaruhi status kesehatan, tingkat pendidikan merepresentasikan tingkat kemampuan seseorang dalam memperoleh dan memahami informasi kesehatan. ${ }^{16}$

Berdasarkan data yang didapat menunjukkan bahwa responden yang terbanyak terdapat pada penghasilan $<$ UMP dengan 30 orang. Dan status OHI-S dengan responden terbanyak terdapat pada penghasilan <UMP dengan status OHI-S sedang sebanyak 18 orang (60\%) dibandingkan dengan >UMP yang persentasenya lebih besar akan tetapi responden yang jauh lebih sedikit dengan jumlah hanya 5 orang $(62,50 \%)$. Hal ini dapat dilihat bahwa tingkat penghasilan yang lebih tinggi memiliki kesehatan gigi dan mulut yang lebih baik dibandingkan dengan tingkat penghasilan rendah. Penelitian ini sejalan dengan penelitian yang dilakukan oleh Alayyanur dsan Pudjirahardjo $^{17}$ di Puskesmas Jemursari Surabaya pada tahun 2013, bahwa seseorang yang memiliki penghasilan yang tinggi sering memeriksakan kebersihan mulutnya di puskesmas dibandingkan dengan seseorang yang memiliki penghasilan lebih rendah yang kurang memeriksakan giginya di puskesmas.

Tingkat penghasilan yang baik memungkinkan anggota keluarga untuk memperoleh kebutuhan-kebutuhan tersebut. Keadaan ekonomi atau penghasilan memegang peranan penting dalam meningkatkan status kesehatan keluarga. Tingkat penghasilan yang tinggi akan meningkatkan upaya pemanfaatan pelayanan kesehatan dan pencegahan penyakit. Demikian juga dengan tingkat penghasilan yang rendah akan berdampak pada kurangnya pemanfaatan pelayanan kesehatan dalam hal pemeliharaan kesehatan karena daya beli obat maupun biaya transportasi dalam mengunjungi pusat pelayanan kesehatan.

\section{SIMPULAN}

Status kebersihan gigi dan mulut pada nelayan di kelurahan Bahu Kecamatan Malalayang Kota Manado Sulawesi Utara menunjukkan:

1. Berdasarkan karakteristik usia paling banyak ditemui pada kategori usia 36-45 tahun yang memiliki status OHI-S sedang.

2. Berdasarkan pengetahuan tertinggi ditemui pada responden dengan kategori pengetahuan baik dengan status OHI-S sedang.

3. Berdasarkan pendidikan paling banyak ditemukan pada responden dengan tingkat pendidikan SMA dengan status OHI-S sedang.

4. Berdasarkan penghasilan paling banyak ditemukan pada responden dengan penghasilan lebih kecil dari UMP yang termasuk dalam kategori status OHI-S sedang.

\section{SARAN}

1. Bagi Nelayan: diharapkan agar lebih memperhatikan dan menjaga kebersihan gigi dan mulutnya dengan menyikat gigi secara teratur dan benar, serta menjadikan sikat gigi dan bahan alat kebersihan gigi dan mulut lainnya sebagai bahan utama yang dapat diperhatikan dan di bawah dalam aktivitas keseharian sebagai nelayan.

2. Bagi Pemerintah: diharapkan lebih memperhatikan derajat kesehatan gigi dan mulut bagi para nelayan melalui program-program kesehatan gigi dan mulut serta penyediaan sarana dan prasarana untuk menunjang pelaksanaan program tersebut.

3. Bagi Tenaga Kesehatan: diharapkan dapat memberikan penyuluhan tentang kesehatan gigi dan mulut bagi para nelayan sehingga terjadi peningkatan perilaku seperti kebiasaan yang baik dan bisa meminimalisir terjadinya masalah kesehatan gigi dan mulut.

\section{DAFTAR PUSTAKA}

1. Taufik A. Agama, Etos Kerja dan Perkembangan Ekonomi. Jakarta: 
LP3ES bekerja sama dengan YOI dan Leknas-LIPI; 1993.

2. Apridar. Ekonomi Kelautan dan Pesisir. Yogyakarta: Graha Ilmu, 2011.

3. Nurhati H. Wilayah pesisir coastal zone. Available from: http://sastrakelabu.wordpress.com/20 10/04/15/wilayah-pesisir-coastale> (cited Desember 2012)

4. Kusnadi. Kebudayaan Masyarakat Nelayan. Available from: www.bappenas .go.id/index.php/download_file/view/ 10691/2407 (cited April 2014).

5. Sondang P, Hamada T. Menuju gigi dan mulut sehat. Medan: USU Press, 2008; p. 69-70.

6. Riskesdas. Riset Kesehatan Dasar, Badan penelitian dan pengembangan kesehatan, Republik Indonesia. Jakarta: Laporan Nasional; 2013.

7. Seiham A. Oral health, general health and quality of life. Bulletin of WHO. 2005;83(9):644.

8. Jalil F, Akbar. Keadaan kebersihan mulut dan peradangan gingiva nelayan di pulau Kodingareng [Skripsi]. Makassar: $\quad$ FKG-Universitas Hasanuddin; 2013. p. 93-113.

9. Rasyid H. Penilaian hasil belajar. [online]. Available from URL: http://id.shvoong.com/socialsciences/ education/2010/12. Bandung: CV. Wacana Prima, 2008.

10. Indirawati NT, Lelly A. Worker Oral Hygiene Indeks in the Industrial Area in Pulo Gadung. Sistem Kesehatan. 2013;16(2):168-75.
11. Yulianti RP, Abi M. Hubungan Antara Pengetahuan Orang Tua Tentang Kesehatan Gigi dan Mulut Dengan Kejadian Karies Gigi di SDN V Jataen Karanganyar. FIK UMS; 2010. http://repository.usu.ac.id/bitstream/1 23456789/51667/2/Reference.pdf

12. Mubarak WI. Promosi Kesehatan. Jogjakarta: Graha Ilmu, 2007.

13. Setiadi. Ilmu Sosial Budaya Dasar. Jakarta: Perdana Media Grup, 2002.

14. Sintawati FX, Tjajah I. Faktor-faktor yang mempengaruhi kebersihan gigi dan mulut masyarakat DKI Jakarta Tahun 2007. Jurnal Ekologi Kesehatan. 2008:8(1):860-73.

15. Setiawati ER. Hubungan Sosial Ekonomi dengan Status Kehilangan Gigi. Makasar: 2013. repository.unhas.ac.id/.../RISKI\%20E RDA\%20SETY

16. Sondang $P$. Hubungan Tingkat Pendidikan Dengan Karies Gigi Pada Ibu-ibu Rumah Tangga Usia 20-45 tahun di Kelurahan Simpang Selayan Medan Tuntungan. 2008. http://www.scribd.com/doc/23103854 /Son-Dang\#scribd

17. Alayyannur PA, Pudjirahardjo WJ. Customer Value Analysis Based On Customer Characteristic In Teeth Clinic of Puskesmas Jemursari Surabaya. Jurnal Administrasi Kesehatan Indonesia. 2013:1(2). http://journal.unair.ac.id/article_5606 _media141_category141.html 